\title{
Development of memantine orodispersible tablets and their in vitro description and biopharmaceutical performance
}

\author{
Carlos Adrián Peñaloza-Becerra ${ }^{1}$, Gabriel Marcelín-Jimenez,2, Mariel Vanessa \\ López-González1 ${ }^{1}$ Ernesto Ortega-Escamilla1', Juan Ernesto Vásquez-Vásquez', Alionka P \\ Ángeles-Moreno², Alberto García-González², Dany Batista-Dieguez ${ }^{3}$ \& Estefanía \\ Rodarte-Valle 3 \\ ${ }^{1}$ Centro AF de Estudios Tecnológicos, SA de CV, Nicolás San Juan 2014, Del Valle, Col del Valle Centro, Del Benito Juárez, 03100 \\ Ciudad de Mexico (CDMX), Mexico \\ ${ }^{2}$ Global Bioanalytical Consulting, SC, Av Insurgentes Sur No 1188, Dpto 203; Col Tlacoquemecatl, 03200 Del Benito Juárez, \\ 03200 CDMX, Mexico \\ ${ }^{3}$ Pharmometrica (Pharmet, SA de CV), Av de las Granjas 972 LC-08A, Col Santa Bárbara, Tecnoparque Azcapotzalco, 02230 \\ CDMX, Mexico \\ * Author for correspondence: Tel.: +52 559127 0111; gabmarcelin@gbioanalytical.com.mx
}

\begin{abstract}
Aim: New approaches are required to improve compliance in older patients with problems in swallowing traditional formulations. A novel memantine orodispersible tablet (ODT) was formulated, and its bioavailability and taste acceptability were evaluated. Materials \& methods: In vitro characterization of ODT comprised dispersion in simulated saliva prior to dissolution assay in a limited volume of biorelevant media. A single oral dose of 20-mg memantine ODT exhibits similar bioavailability to that of an immediate release 20-mg tablet in a healthy population under fasting conditions. Results: $90 \%$ confidence interval for $C_{\max }$ was of $96.78-106.52 \%$ and $98.27-104.78 \%$ for $A \cup C_{0-72}$. An applied palatability survey showed exceptional acceptance of the formulation. Conclusion: Memantine microspheres prepared by a solid-dispersion technique results in ODT with adequate biopharmaceutical performance.
\end{abstract}

First draft submitted: 5 January 2018; Accepted for publication: 2 February 2018; Published online: 15 February 2018

Keywords: aging $\bullet$ Alzheimer's disease $\bullet$ bioavailability $\bullet$ memantine orodispersible tablets $\bullet$ palatability

According to the WHO, the aging of a population "should be considered a success of public health policies and socioeconomic development, but it also constitutes a challenge for its society, which must be adapted in order to maximize the health and functional capacities of older citizens". It has been predicted by the Mexican Population Council that by the year 2050, women older than 60 years will comprise $23.3 \%$ of the total female population and males with similar ages will make up $19.5 \%$ of the total male population. Aging is accompanied by multimorbidity, including mental illness such as depression (17.6\%), cognitive impairment (7.3\%) and several types of dementia (7.9\%) [1].

During the therapeutics of the geriatric population, several problems become evident, such as correct understanding of instructions, difficulties in opening containers, breaking tablets manually and swallowing oral solid formulations. In this context, the EMA has worked on a paper entitled 'Quality aspects in the pharmaceutical development of medicines for older people'. This reflective paper reports on three key aspects concerned with the practical use of medicines for geriatric population including the following: storage conditions, easy-to-open containers and novel pharmaceutical formulations, such as minitablets and orodispersible tablets (ODTs) [2].

Under these premises, declaring dementia as the first cause of impairment in older people, the WHO has considered the treatment of dementia as a public health priority for social assistance. Recent efforts to formulate novel transdermal systems for memantine have been published [3]. Memantine (3,5-dimethyladamantan-1-amine; CAS no. 19982-08-2) is a noncompetitive N-methyl-D-aspartate-receptor antagonist effective in the treatment of moderate-to-severe dementia, including the symptoms of Alzheimer's disease, with several advantages over other antidementia drugs [4] and it has recently been implicated in the therapeutics of obsessive compulsive disorders [5]. 
The development of memantine hydrochloride ODTs is a recent therapeutic strategy [6]. ODT has become a technology for easy administration and swallowing, with taste acceptability for geriatric patients, which results in better treatment compliance [7]. Memantine $\mathrm{HCl}$ is a highly soluble $\left(35 \mathrm{mg} / \mathrm{ml}\right.$ in water at $\left.20^{\circ} \mathrm{C}\right)$ and highly permeable molecule (corresponding to biopharmaceutical class $\mathrm{I} ; \log \mathrm{P}=3.28 ; \mathrm{pKa}=10$ ). It is recognized by several regulatory agencies that bioequivalence can be biowaived by proper dissolution assays. However, the Mexican Regulatory Agency establishes that for novel formulations not previously commercialized in Mexico, it is essential to demonstrate bioequivalence with respect to a reference formulation available on the Mexican market.

Thus, the aims of present work were to describe the strategies in the development of in vitro assays to evaluate the dissolution performance of a novel memantine ODT formulation, as well as its biopharmaceutical behavior during a comparative bioavailability trial in Mexican healthy volunteers, and the acceptability of the ODT during an organoleptic survey.

\section{Materials \& methods}

Chemicals \& reagents

Memantine (Olainfarm; Riga, Latvia) and amantadine (Sigma-Aldrich; Toluca, Mexico) standards were kindly supplied by Productos Científicos SA de CV (Mexico City, Mexico). HPLC-grade acetonitrile, in addition to hydrochloric acid, sodium chloride, phosphoric acid, monobasic and dibasic potassium phosphate and amylamide analytical grades, as well as Triton ${ }^{T M} \mathrm{X}-100$ and Tween ${ }^{T M}$ 80, were purchased from JT Baker (Mexico City, Mexico), while formic acid was obtained from Sigma-Aldrich-Fluka (Toluca, Mexico). Ultrapure water was obtained from a Milli-Q ${ }^{T M}$ system (Millipore, MA, USA).

Akatinol ${ }^{\circledR} 20 \mathrm{mg}$ immediate release tablets (Merz Pharma; Mexico City, Mexico) were used as reference product, while memantine $20 \mathrm{mg}$ ODTs (Productos Científicos SA de CV, Carnot Laboratorios; Mexico City, Mexico) were the test products.

\section{Formulation of orodispersible tablets}

Memantine ODTs were formulated employing common excipients for this technology (crospovidone and starch sodium glycolate as disintegrants, microcrystalline cellulose and mannitol as diluents, talcum powder as lubricant, sucralose and a strawberry/mint flavor). Memantine microspheres were prepared by a solid-dispersion technique with stearyl alcohol, using Eudragit ${ }^{\mathrm{TM}}$ E PO (Evonik Health Care; IN, USA) as taste masker. 20-mg memantine ODTs were round, flat, slotted tablets with a hardness of $30.4 \mathrm{~N}$, an average weight of $400 \mathrm{mg}$, a diameter of $9 \mathrm{~mm}$ and a thickness of $3 \mathrm{~mm}$.

\section{Dissolution tests \\ Pharmacopeic conditions}

Akatinol and first evaluations of ODT were performed by using US Pharmacopeia conditions for solid forms of memantine [8]. Briefly, the method consists of assay having six units of each formulation in $900 \mathrm{ml}$ of dissolution media ( $\mathrm{HCl} 0.1 \mathrm{~N}$ and $2 \mathrm{~g} / \mathrm{l}$ of $\mathrm{NaCl}$ ), by using apparatus I at 100 r.p.m., $37^{\circ} \mathrm{C}$, sampling $10 \mathrm{ml}$ without reposition at 10, 20, 30 and $45 \mathrm{~min}$. Dissolution instruments employed were Distek 2500 (NJ, USA).

\section{Discriminative media}

In order to establish a more discriminative assay, the following conditions were proposed that emulate the physiological environment inside the bowel in terms of small volumes, $\mathrm{pH}$, osmolality and surface tension. Methodology previously reported $[9,10]$ was adapted as follows: apparatus II at 25 r.p.m., $250 \mathrm{ml}$ dissolution media, sampling $3 \mathrm{ml}$ without reposition at 1, 3, 5, 10, 20 and $30 \mathrm{~min}$. Dissolution media were as follows: $\mathrm{HCl} 0.1 \mathrm{~N}$, Triton X-100 (0.1\%), $\mathrm{NaCl} 2 \mathrm{~g} / \mathrm{l}, \mathrm{pH}=1.2$, or $\mathrm{HCl} 0.1 \mathrm{~N}$, Tween 80 (0.1\%), $\mathrm{NaCl} 2 \mathrm{~g} / \mathrm{ml}, \mathrm{pH}=1.2$.

\section{Simulated saliva}

At last, to resemble the whole bucal dispersion and dissolution process, a dispersion step in simulated saliva was included only for ODT prior to the dissolution assay. ODTs were placed in $1 \mathrm{ml}$ of simulated saliva $(\mathrm{NaCl} 8 \mathrm{~g}$, monobasic potassium phosphate $0.19 \mathrm{~g}$ and dibasic potassium phosphate $2.38 \mathrm{~g}$, all in $11 \mathrm{lof}$ ultrapure water, and adjusted to $\mathrm{pH}=6.8$ ) for $1 \mathrm{~min}$; after that, both dispersed ODT and Akatinol were added to discriminative media to continue with dissolution tests [11]. 


\section{Quantification of memantine in dissolution samples}

HPLC (Waters 2695; MA, USA) coupled with a refractive index detector (Waters 2414RI) was employed, interfaced by Empower ${ }^{\circledR}$ software (MA, USA). Memantine separation was carried out by means of a Hypersil Gold C18 column $(4.6 \times 150 \mathrm{~mm}, 5 \mu \mathrm{m}$ particle size; Thermo Fisher Scientific, MA, USA). Flow rate was maintained at $1.0 \mathrm{ml} / \mathrm{min}$ under isocratic conditions, with a mobile phase of aqueous buffer $(1 \mathrm{ml}$ of phosphoric acid plus $1 \mathrm{ml}$ of amylamine in 11 of ultrapure water)/acetonitrile $(80: 20 \mathrm{v} / \mathrm{v})$. Column was maintained at $40^{\circ} \mathrm{C}$ and autosampler temperature was set at $10^{\circ} \mathrm{C}$. Volume of sample injection was $5 \mu \mathrm{l}$, having a complete run of $3 \mathrm{~min}$. Memantine was quantified by using calibration curves validated for each dissolution medium, in a range of $40-120 \%$ dissolution [12].

\section{Comparative bioavailability trial}

18 healthy Mexican volunteers participated in this study: 7 women and 13 men. Inclusion criteria were BMI between 18 and $27 \mathrm{~kg} / \mathrm{m}^{2}$, age between 18 and 55 years, normal electrocardiogram and clinical history, laboratory values within normal ranges (hematology, blood biochemistry, urine analysis and liver function), nonsmokers and negative for AIDS, hepatitis B and C, and in women, for pregnancy tests. Exclusion conditions comprise allergic history to any component of the formulations assayed, pregnancy, active alcoholism, positive results for the rapid urine assay of cocaine, barbiturates, benzodiazepines, methamphetamines and tetrahydrocannabinol, and any serious health condition that would affect the evolution of the study. Withdrawal situations throughout the study considers any kind of hypersensitivity reactions, loss of two or more samples around $C_{\max }$, vomiting between administration time and twofold $\mathrm{T}_{\max }$ or any diet transgression [13].

All volunteers granted their signed informed consent forms, and were medically monitored closely throughout the entire study. Current protocol was reviewed and authorized by the Global Bioanalytical Consulting Ethics Committee, registered in the Mexican Regulatory Agency (COFEPRIS registration trial no. 163300410B0263/2016) and conducted with full compliance with the latest Declaration of Helsinki and in agreement with the Good Clinical Practice defined by the International Conference on Harmonization.

The clinical study was controlled, randomized, simple-blinded to the analytical investigator, cross-over, two periods (sampling truncated up to $72 \mathrm{~h}$ per period, with 18 days of washout period in between), two treatments (20-mg memantine ODT or Akatinol $20 \mathrm{mg}$ immediate release tablet), under fasting conditions. Experimental groups had the same number of volunteers randomly assigned to each treatment sequence.

Volunteers presented the day prior to drug administration. They received dinner at 8:00 pm and fasted overnight $(12 \mathrm{~h})$. An intravein catheter was set in a forearm area the next morning. At 8:00 am in the case of volunteers receiving Akatinol, a single dose was taken with $250 \mathrm{ml}$ of water; in the case of volunteers receiving ODT, they washed their mouths briefly with $20 \mathrm{ml}$ of tap water, swallowed this and placed one ODT on the tongue, making gentle motions to disperse the tablets within the closed mouth - no chewing. Then, the particles were completely swallowed and $230 \mathrm{ml}$ of water was drunk in order to compare the bioavailability of both formulations under the same conditions.

Approximately $6 \mathrm{ml}$ of blood was drawn from each study participant for each sample through the catheter at $0 \mathrm{~h}$ (before administration) and at 1, 2, 3, 4, 5, 5.5, 6, 6.5, 7, 7.5, 8, 9, 12, 24, 48 and $72 \mathrm{~h}$ after memantine administration. Samples were taken in vacuum heparinized tubes and centrifuged at 4000 r.p.m. for 5 min at $20^{\circ} \mathrm{C}$ for plasma separation. Plasma was collected in identified cryovials and stored at $-70^{\circ} \mathrm{C}$ until memantine quantitation.

\section{Determination of memantine in human plasma}

Sample extraction, chromatography and spectrometer settings were adjustments of previously reported articles [14,15]. Shortly, $100 \mu \mathrm{l}$ of plasma was fortified with $20 \mu \mathrm{l}$ of amantadine solution (internal standard: $200 \mathrm{ng} / \mathrm{ml}$ in $60 \%$ methanol), alkalinized with $20 \mu \mathrm{l}$ of a $10 \%$ solution of ammonium hydroxide, proteins were precipitated with $300 \mu \mathrm{l}$ of acetonitrile $\left(4^{\circ} \mathrm{C}\right)$ and centrifuged; supernatant was mixed with water in the ratio $1: 1$ and $2 \mu \mathrm{l}$ was introduced into the ultraperformance liquid chromatograph (UPLC).

UPLC (Acquity ${ }^{T M}$ Class-I/, Waters Co, MA, USA) coupled with a tandem mass spectrometer (Xevo ${ }^{T M}$ TQ-S, Waters Micromass, Manchester, UK) was employed, interfaced by MassLynx ${ }^{\top \mathrm{M}}$ version 4.1 software. Memantine and amantadine were separated from possible endogenous interferences employing a BEH C18 column $(2.1 \times 50 \mathrm{~mm}$, $1.7 \mu \mathrm{m}$ particle size, acquity UPLC, Waters; Dublin, Ireland). Flow rate was fixed at $0.45 \mathrm{ml} / \mathrm{min}$ under isocratic conditions, and the mobile phase was optimized as $0.1 \%$ aqueous formic acid $/ 0.1 \%$ formic acid in acetonitrile 
$(85: 15 v / v)$. Column was maintained at $40^{\circ} \mathrm{C}$ and autosampler temperature was set at $10^{\circ} \mathrm{C}$. Under these conditions, a complete run took $5 \mathrm{~min}$.

Quantitation was done by positive electrospray, selecting the ion transitions of $\mathrm{m} / \mathrm{z}^{+1} 180.20>163.15$ and $152.20>135.15$ for memantine and amantadine, respectively.

Method was fully validated according to Mexican guidelines [13] and proved to be linear, precise and accurate between 0.8 and $80 \mathrm{ng} / \mathrm{ml}$ of memantine.

\section{Palatability survey}

A memantine ODT palatability and acceptability survey (based on Nilausen et al., 2011) was applied to the 18 volunteers who participated in the bioequivalence trial, during the period of test-product intake [16]. The survey comprised 35 questions grouped in five items, with the intention of evaluating the following: physical properties (size of tablet, texture, velocity of disintegration and amount of lumps); perception of taste (initial and residual taste); comfort of use (compared with other solid presentations); ease of use (ease of opening and handling); and treatment compliance (compared with other formulations).

Survey responses were obtained through an analog-visual-validated linear scale of $10 \mathrm{~cm}$, where possible responses could fall between opposite values (completely disagree-fully agree) that were transformed into a numerical scale ranging from 0 to 10 . Arithmetic mean and $\% \mathrm{CV}$ were calculated for each question in order to establish the value of the item, and \%CV values were used to describe agreement between questions and items. Values of $<35 \% \mathrm{CV}$ were assigned as high agreement, 35\% $<\% \mathrm{CV}<70 \%$ were assigned as moderate agreement and $>70 \%$ were assigned as poor agreement.

\section{Statistical analysis}

For dissolution profiles, an independent time series approach was employed to compare assays when differences were not evident.

Pharmacokinetic parameters were calculated from analyzed plasma obtained from single dose-receiving volunteers, utilizing Phoenix WinNonlin version 6.4 software (Certara LP, NJ, USA), considering a noncompartmental model. Plasma elimination half-life $\left(\mathrm{t}_{1 / 2}\right)$, AUC until $72 \mathrm{~h}\left(\mathrm{AUC}_{0-72}\right)$ and elimination constant $\left(\mathrm{k}_{\mathrm{e}}\right)$ were software outputs. $\mathrm{C}_{\max }$ and $\mathrm{T}_{\max }$ were obtained experimentally.

To evaluate fixed effects such as period, sequence and formulation, we utilized analysis of variance (ANOVA) for a standard $2 \times 2$ crossover design. Pharmacokinetic differences were assayed based on a bioequivalence approach, building 90\% CI of log-transformed relationships for $\mathrm{C}_{\max }$ and $\mathrm{AUC}_{0-72}$ between both formulations. Statistical analyses were carried out using Phoenix WinNonlin and Minitab TM version 16 software (Minitab, State College, PA, USA).

Concerning palatability survey, measurement of consistency inside items was validated by the use of Cronbach's alpha [17]. Possible differences between sequences of administration were assayed by the Student's $t$-test for independent samples.

\section{Results \& discussion}

Dissolution assays

The different results obtained during dissolution assays are depicted in Figure 1. As can be observed, pharmacopeic media were not able to discriminate solubility differences between the formulations (Figure 1A), confirming that such conditions are adequate for quality-control purposes, but that they do not resemble physiological conditions.

These results compelled the development of teamwork in order to assay more discriminative media. The new media adopted, attempted to simulate closer conditions that reflected with dissolution microenvironment in which the tablets would be dissolved, such as small volume of media, acidic $\mathrm{pH}$, osmolality, surface tension of bowel fluids, which were formulations that would disintegrate and deliver the memantine. First results with the medium containing Triton X-100 did not correspond to the expected behavior for both the formulations because the reference product exhibited faster delivery compared with ODT (Figure 1B).

Thus, it was decided to change Triton X-100 (surface tension of $42.5 \mathrm{mN} / \mathrm{m}$ ) for Tween 80 (surface tension of $41 \mathrm{mN} / \mathrm{m}$ ), the latter closely simulating the tension produced by endogenous surfactants. In addition to this, noncompressed powders for ODT were assayed in order to determine whether lack of delivery was due to certain excipients, or caused by the compression process (Figure 1C). It was evidenced that slow delivery of memantine was related with a limited disintegration step of the ODT, which was not observed with the powder. 
(A)

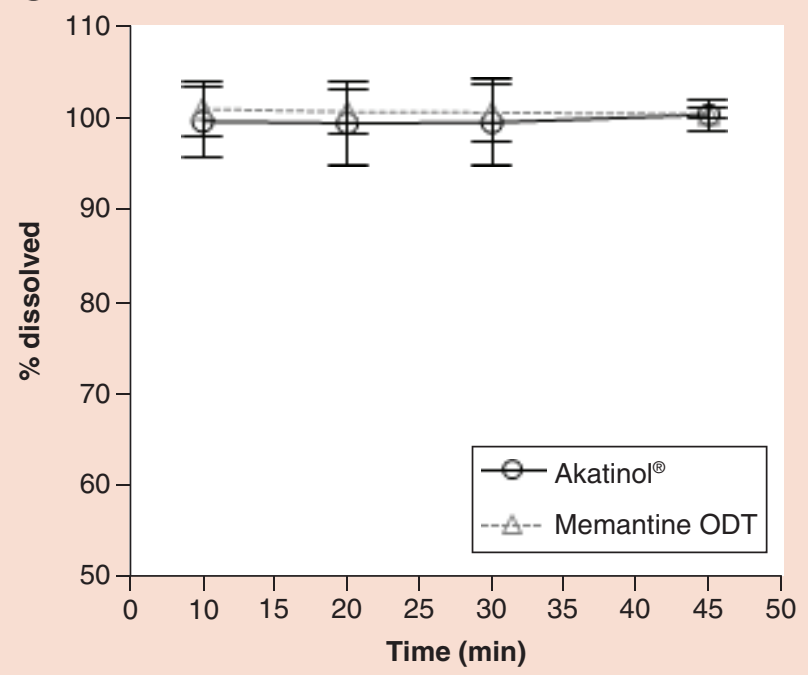

(C)

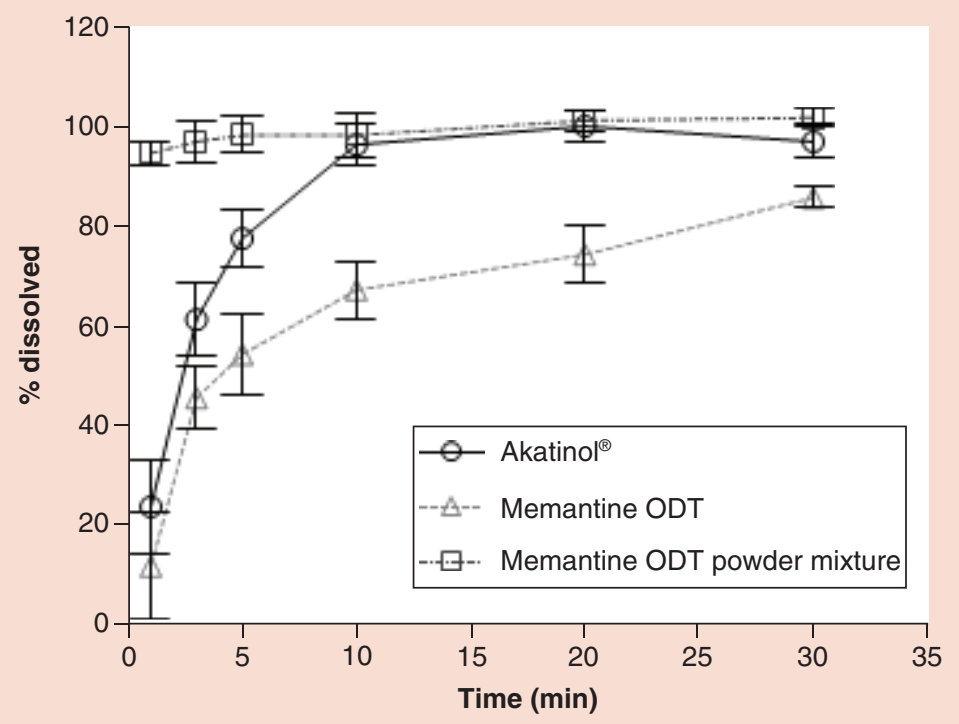

(B)

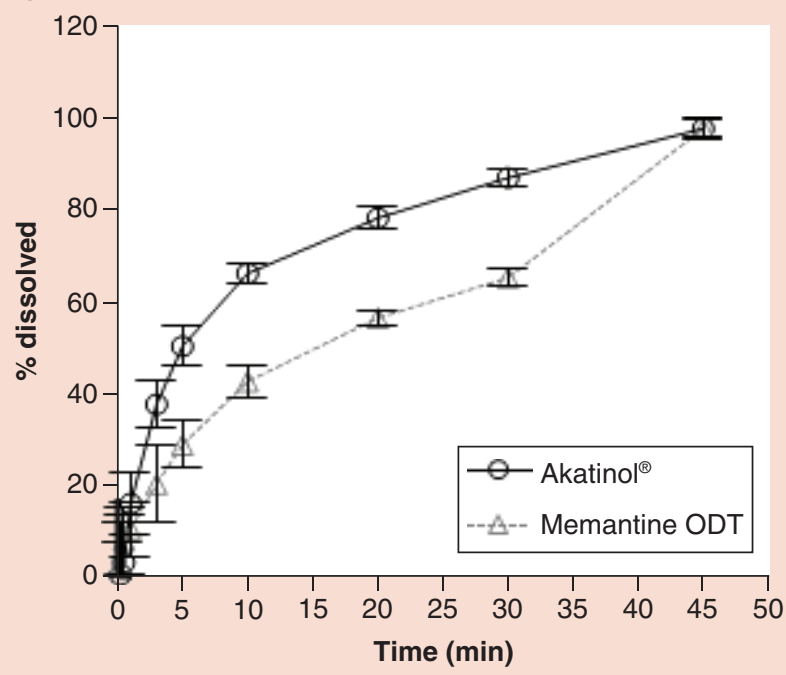

(D)

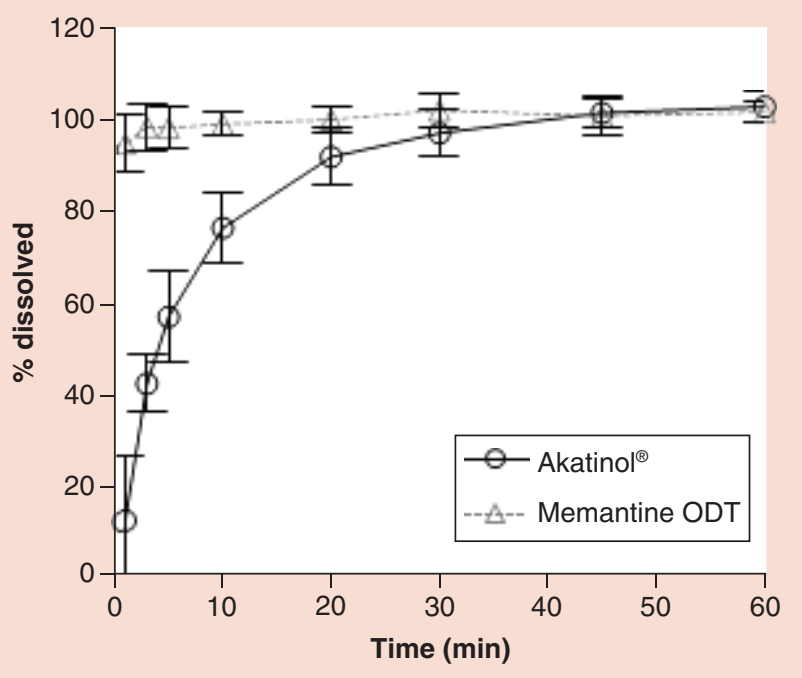

Figure 1. Dissolution profiles of memantine $20 \mathrm{mg}$ orodispersible tablets and Akatinol ${ }^{\circledR}$ immediate release 20 -mg tablets. (A) In $0.1 \mathrm{M}$ $\mathrm{HCl}$ United States Pharmacopeia medium, having apparent similarities despite different mechanisms of delivery; $(\mathbf{B}) \mathrm{In} 0.1 \mathrm{M} \mathrm{HCl}, \mathrm{NaCl}$ and $0.1 \%$ Triton $^{T M} \mathrm{X}-100(\mathrm{pH}=1.2)$ as first 'physiological medium' approach; (C) In $\mathrm{HCl} 0.1 \mathrm{M}, \mathrm{NaCl}$ and $0.1 \%$ Tween ${ }^{T M} 80$ ( $\left.\mathrm{pH}=1.2\right)$, including ODT powder mixture, in order to discriminate the influence of excipients or ODT compression on dissolution; (D) In simulated saliva as a disintegration step prior to the dissolution in ' $C$ ' conditions.

ODT: Orodispersible tablet.

In order to mimic the normal conditions for ODT administration, we proposed to previously disintegrate the ODT in $1 \mathrm{ml}$ of simulated saliva for $1 \mathrm{~min}$, and then add the dispersed material into the Tween 80 dissolution media. It is noteworthy (Figure 1D) that dissolution profiles agree with the pharmaceutical formulations. While ODT possesses rapid and complete dissolution during the first times, the reference product demonstrates a humectationdisintegration period with gradual dissolution that at around $30 \mathrm{~min}$ is quite similar at the different ODT levels, due to which the memantine is considered a highly soluble molecule. It would be expected that such differences would not be relevant during the in vivo assay.

\section{Comparative bioavailability trial}

The concentration-time profiles of the 18 volunteers for memantine up to $72 \mathrm{~h}$ are presented in Figure 2. All 


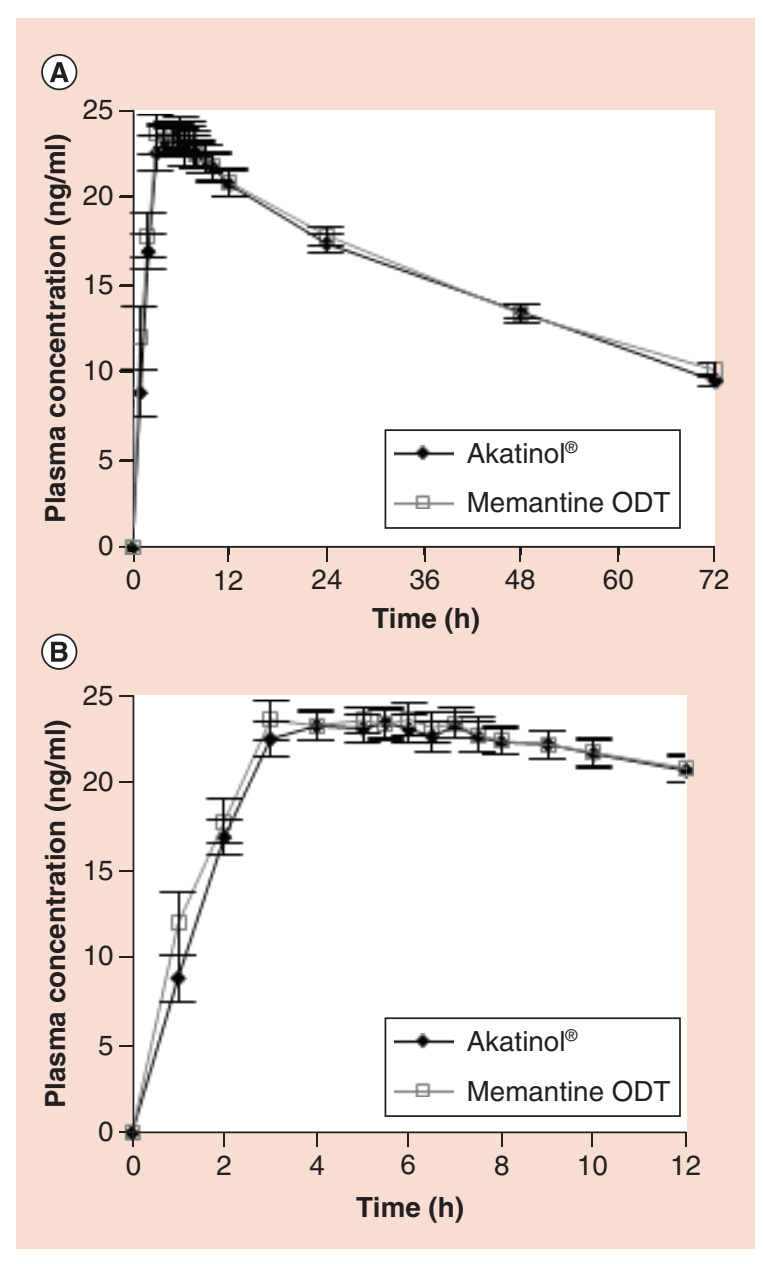

Figure 2. Memantine plasma concentration-time profile of 18 healthy Mexican volunteers, after an oral, single-dose administration of one $20 \mathrm{mg}$ immediate release tablet of Akatinol ${ }^{\circledR}$ (reference product in Mexican market) or memantine orodispersible tablet (test product), under fasting conditions. (A) Full sampling truncated up to $72 \mathrm{~h}$; (B) Pharmacokinetic profiles of the first $12 \mathrm{~h}$. ODT: Orodispersible tablet.

\begin{tabular}{|c|c|c|c|c|c|}
\hline & Mean & SD & \%CV & Minimal & Maximal \\
\hline \multicolumn{6}{|l|}{ Memantine ODT } \\
\hline $\mathrm{T}_{\max }(\mathrm{h})$ & 4.97 & 2.018 & 40.587 & 1 & 7.5 \\
\hline $\mathrm{C}_{\max }(\mathrm{ng} / \mathrm{ml})$ & 25.491 & 4.655 & 12.261 & 17.226 & 34.638 \\
\hline $\mathrm{k}_{\mathrm{e}}\left(\mathrm{h}^{-1}\right)$ & 0.013 & 0.003 & 21.995 & 0.009 & 0.018 \\
\hline$t_{\frac{1}{2}}(h)$ & 58.578 & 12.824 & 21.893 & 38.885 & 80.818 \\
\hline$A \cup C_{0-72}(\mathrm{ng} \cdot \mathrm{h} / \mathrm{ml})$ & 1134.092 & 168.428 & 14.851 & 825.306 & 1446.796 \\
\hline \multicolumn{6}{|l|}{ Akatinol $^{\circledR}$} \\
\hline $\mathrm{T}_{\max }(\mathrm{h})$ & 5 & 1.871 & 27.417 & 2 & 7.5 \\
\hline $\mathrm{C}_{\max }(\mathrm{ng} / \mathrm{ml})$ & 24.931 & 3.346 & 13.421 & 17.384 & 29.808 \\
\hline$k_{e}\left(h^{-1}\right)$ & 0.013 & 0.003 & 19.503 & 0.009 & 0.019 \\
\hline$t_{\frac{1}{2}}(h)$ & 55.871 & 10.064 & 18.014 & 36.118 & 77.509 \\
\hline$A \cup C_{0-72}(\mathrm{ng} \cdot \mathrm{h} / \mathrm{ml})$ & 1113.515 & 135.005 & 12.124 & 915.021 & 1378.009 \\
\hline
\end{tabular}

ODT: Orodispersible tablet; SD: Standard deviation.

calculated pharmacokinetic $(\mathrm{PK})$ parameters are summarized in Table 1 . As can be noted, no significant differences were observed in terms of velocity of absorption and total amount absorbed (Table 2), respectively. Thus, during ODT formulation, it appears that oral disintegration and rapid dissolution in the bowel did not to exert any influence on the bioavailability of memantine. 
Table 2. Statistics bioequivalence of memantine $20 \mathrm{mg}$ orodispersible tablets and Akatinol ${ }^{\circledR}$ 20-mg immediate release tablets.

\begin{tabular}{llll}
\hline Parameter & (\%) Intrasubject CV & \multicolumn{2}{c}{ Statistic power Confidence intervals } \\
\cline { 2 - 4 } & & Lower & Upper \\
\hline $\mathrm{C}_{\max }(\mathrm{ng} / \mathrm{ml})$ & 8.250 & 95.992 & 108.284 \\
\hline $\mathrm{AC}_{0-72 \mathrm{~h}}(\mathrm{ng} * \mathrm{~h} / \mathrm{ml})$ & 5.510 & 100.232 & 111.015 \\
\hline
\end{tabular}

Concerning pharmacokinetic data obtained in Mexican population, it is interesting to note differences with previously published information. In a healthy Indian population [14], the study participants were administered with a single oral dose of $10 \mathrm{mg}$ under fasting conditions, reaching a mean $\mathrm{C}_{\max }$ of $14.39 \mathrm{ng} / \mathrm{ml}$, (approximately $44 \%$ less with the half dose used in this work), while $\mathrm{T}_{\max }$ was $7.5 \mathrm{~h}$ with an elimination half-life of $49 \mathrm{~h}$. Moreover, in a Brazilian study conducted under the same conditions, with a $10-\mathrm{mg}$ oral dose, the $\mathrm{C}_{\max }$ reported was $21.6 \mathrm{ng} / \mathrm{ml}$ (86.4\% of $\mathrm{C}_{\max }$ acquired in Mexican, but using one half of the dose), with a delayed $\mathrm{T}_{\max }$ of $8 \mathrm{~h}$ and a shorter $\mathrm{t}_{\frac{1}{2}}$ of $43 \mathrm{~h}$ [18]. At last, the present data appear quite to those obtained in a Chinese trial [19], where the authors reported a $\mathrm{C}_{\max }$ of $25.34 \mathrm{ng} / \mathrm{ml}$, with a $\mathrm{T}_{\max }$ of $6.8 \mathrm{~h}$ and a $\mathrm{t}_{\frac{1}{2}}$ of $62 \mathrm{~h}$ with a single oral dose of $20 \mathrm{mg}$.

Although it is known that memantine is not metabolized, all of these apparent demographic differences in bioavailability should be explored more thoroughly, and its clinical relevance must be discussed in the face of the new findings on its cellular mechanisms associated with the prevention of the expression of cell-adhesion molecules induced by proinflammatory signals in the endothelium of human brain microvasculature, which is linked to cognitive impairment and dementia during aging [20].

\section{Palatability survey}

The survey was fully validated employing placebo ODT with volunteer personnel of Pharmometrica, and no statistical effect of the sequence-of-administration in the responses was demonstrated.

The most concordant answers in terms of mean values in the analog-visual scale were (detected in decreasing order):

- ODTs have a nice flavor;

- ODTs did not leave an unpleasant aftertaste or sensation in the mouth;

- ODTs would be preferred over common tablets and other pharmaceutical forms, with higher compliance for prolonged treatments;

- ODTs are easily handled and did not break into the blister or in the fingers.

\section{Conclusion}

It might be considered that pharmacopeic dissolution conditions have quality-control purposes, and that in many of the cases, they do not have a discriminative capacity to distinguish differences in the delivery of the active pharmaceutical ingredients from the pharmaceutical formulation that could impact the bioavailability of the drugs. The development and adoption of the discriminative dissolution assay must resemble the physiological conditions, such as small volumes, slower agitation speeds, similar surface tension, $\mathrm{pH}$ and temperature, as well as consider a previous disintegration step in the case of ODT.

In the case of the ODT developed, they exhibited adequate palatability characteristics and were well accepted in a sample of healthy volunteers. Memantine ODTs were bioequivalent with the reference product and the pharmacokinetics of memantine in Mexican population exhibits slight differences with those previously reported in other populations.

With this biopharmaceutical development and human pharmacokinetic and palatability characterization, memantine ODT has established a new approach to be used as a dosage form with value proposition in concordance with EMA 'Quality aspects in the pharmaceutical development of medicines for older people'. Further research should be conducted in order to assess patient preference.

\section{Future perspective}

Considering the aging of global population, we must observe a trend in the development and commercialization of pharmaceutical formulations such as ODT, minipills, transdermic patches and so on for geriatric population. 
During those developments, researchers must create in vitro assay that resembles as close as possible the physiological conditions during drug delivery. Such assays should include not only media ( $\mathrm{pH}$, salinity, osmolality, tensoactive presence and limitaintg volume), but also new apparatus that can simulate disintegration, bowel empting, peristaltic motion and gastroenteric reabsorption. Adoption of these technologies will be able to generate stronger in vitro-in vivo correlations.

At last and concerning new insights in the cellular therapeutic mechanism of memantine, it is promissory that it could be used not only in the treatment of Alzheimer's disease, but also in other kinds of dementia and cognitive disorders.

\section{Summary points}

- Aging of global population has been accomplished by an increase in several kinds of dementia, including Alzheimer's disease.

- Modern public health policies must consider the design of pharmaceutical formulations suitable for older patients.

- Developed memantine orodispersible tablet complies with the quality aspects in the pharmaceutical development of medicines for older people.

- During formulation characterization, it is very convenient to develop biorelevant conditions during dissolution assays that mimic the physiological environment of the drug delivery, instead of pharmacopeic methodology.

- Memantine orodispersible tablet was bioequivalent to $20-\mathrm{mg}$ immediate release tablet, having advantages in flavor and handling that may result in a better treatment compliance.

Financial \& competing interests disclosure

This study was partially funded by Productos Científicos, SA de CV. The authors have no other relevant affiliations or financial involvement with any organization or entity with a financial interest in or financial conflict with the subject matter or materials discussed in the manuscript apart from those disclosed.

No writing assistance was utilized in the production of this manuscript.

Ethical conduct of research

The authors state that the clinical protocol was reviewed and approved by an independent Ethics Committee. In addition, the authors obtained COFEPRIS approval for the conduction of present study. Volunteers signed informed consent, which was formulated according to the latest version of the Declaration of Helsinki (64th General Meeting, Fortaleza, Brazil; October 2013).

\section{Open access}

This work is licensed under the Attribution-NonCommercial-NoDerivatives 4.0 Unported License. To view a copy of this license, visit http://creativecommons.org/licenses/by-nc-nd/4.0/

\section{References}

Papers of special note have been highlighted as: • of interest; $\bullet \bullet$ of considerable interest

1. Instituto Nacional de las Mujeres. Situación de las personas adultas mayores en Mexico (2015). http://cedoc.inmujeres.gob.mx/documentos_download/101243_1.pdf

2. van Riet-Nales DA, Hussain N, Sundberg KA et al. Regulatory incentives to ensure better medicines for older people: from ICH E7 to the EMA reflection paper on quality aspects. Int. J. Pharm. 512(2), 343-351 (2016).

-. Shares the state-of-the-art of different approaches for new formulations directed to older patients.

3. del Río-Sancho S, Serna-Jimenez CE, Sebastián-Morelló M et al. Transdermal therapeutic systems for memantine delivery. Comparison of passive and iontophoretic transport. Int. J. Pharm. 517(1-2), 104-111 (2017).

4. Fukui Y, Hishikawa N, Ichinose J et al. Different clinical effect of four antidementia drugs for Alzheimer's disease patients depending on white matter severity. Geriatr. Gerontol. Int. 17(11), 1765-2287 (2017).

- Offers an actual landscape in the pharmacological treatment of Alzheimer's disease.

5. Marinova Z, Chuang DM, Fineberg N. Glutamate-modulating drugs as a potential therapeutic strategy in obsessive-compulsive disorder. Curr. Neuropharmacol. 15(7), 977-995 (2017).

6. Jeevitha M, Pandey V. Formulation and development of orodispersible tablet of memantine hydrochloride. Int. J. Drug Dev. Res. 8(1), 38-41 (2016). 
7. Deshpande KB, Ganesh NS. Orodispersible tablets: an overview of formulation and technology. Int. J. Pharma. Bio. Sci. 2(1), 726-734 (2011).

8. Memantine hydrochloryde tablets, In: The United States Pharmacopeial. USP 39 \& NF 34, Rockville, MD, USA, 4716-474719 (2016).

9. Vertzoni M, Dressman J, Butler J, Hempenstall J, Reppas C. Simulation of fasting gastric conditions and its importance for the in vivo dissolution of lipophilic compounds. Eur. J. Pharm. Biopharm. 60(3), 413-417 (2005).

10. Zolnik B, Burgess D. In vitro-in vivo correlation on parenteral dosage forms. In: Biopharmaceutics Applications in Drug Development. Rajesh K, Lawrence Y. (Eds.). Springer, Cham, Switzerland, 336-358 (2008).

11. Marques M, Loebenberg R, Almakainzi M. Simulated biological fluids with possible application in dissolution testing. Dissolut. Technol. 18(3), 15-28 (2011).

12. Gupta AK, Patel PK, Vora JJ, Patel S. Analytical method validation of stability-indicating HPLC method for determination of assay of memantine hydrochloride tablets. Int. J. Pharm. Pract. Drug Res. 4(1), 12-14 (2014).

13. Norma Oficial Mexicana NOM-177-SSA1-2013. www.dof.gob.mx/nota_detalle.php?codigo $=5314833 \& f$ echa $=20 / 09 / 2013$

14. Lou HG, Yu LY, Ruan ZR, Jiang B, Chen JL. Quantitative determination of memantine in human plasma by liquid chromatography-tandem mass spectrometry: application to a bioequivalence study. J. Liq. Chromatogr. Relat. Technol. 35(19), 2696-2705 (2012).

15. Konda RK, Challa BR, Chandu BR, Chandrasekhar KB. Bioanalytical method development and validation of memantine in human plasma by high performance liquid chromatography with tandem mass spectrometry: application to bioequivalence study. J. Anal. Methods Chem. 2012(1), 1-8 (2012).

16. Nilausen DO, Zuiker RG, van-Gerven J. The perception and pharmacokinetics of a 20 -mg dose of escitalopram orodispersible tablets in a relative bioavailability study in healthy men. Clin. Ther. 33(10), 1492-1502 (2011).

17. Oviedo H, Campa A. An approach to the use of Cronbach's alpha. Rev. Colomb. Psiquiatr. 34(4), 572-580 (2005).

18. Costa-Cesar I, Duarte Byrro RM, Fernandes de Santana F et al. Bioequivalence study of two oral formulations of memantine tablets in healthy brazilian volunteers after a single dose administration. J. Bioeq. Bioavail. 4(2), 14-17 (2012).

19. Liu MY, Meng SN, Wu HZ, Wang S, Wei MJ. Pharmacokinetics of single-dose and multiple-dose memantine in healthy chinese volunteers using an analytic method of liquid chromatography-tandem mass spectrometry. Clin. Ther. 30(4), 641-653 (2008).

20. Wang F, Zou Z, Gong Y, Yuan D, Chen X, Sun T. Regulation of human brain microvascular endothelial cell adhesion and barrier functions by memantine. J. Mol. Neurosci. 62(1), 123-129 (2017).

- Provides new insights of the molecular mechanisms of memantine. 